\title{
Olfactory Groove Schwannoma: A Case Report
}

\author{
Stylianos Pikis ${ }^{1}$ Yakov Fellig ${ }^{2}$ Emil Margolin ${ }^{3}$
}

${ }^{1}$ Department of Neurosurgery, “Korgialenio-Benakio," The Red Cross Hospital, Athens, Greece

2 Departments of Neurosurgery, Hadassah-Hebrew University

Medical Center, Jerusalem, Israel

3 Departments of Neurosurgery, Hadassah-Hebrew University

Medical Center, Jerusalem, Israel

Indian J Neurosurg 2017;6:153-154.

We would like to report a case of a 71-year-old woman who presented to the neurosurgery clinic due to an incidentally discovered olfactory groove schwannoma. Magnetic resonance image of the brain was obtained $(\mathbf{- F i g} . \mathbf{1 A - C})$. Due to the
Address for correspondence Emil Margolin, MD, PhD, Department of Neurosurgery, Hadassah-Hebrew University Medical Center, P.O. Box 12000, Jerusalem 91120, Israel (e-mail: EmilM@hadassah.org.il).

patient's advanced age and the benign imaging features of the lesion, monitoring was decided upon. However, growth of the lesion was noted on follow-up and gross total resection was done (-Fig. 1D). Histopathology revealed schwannoma

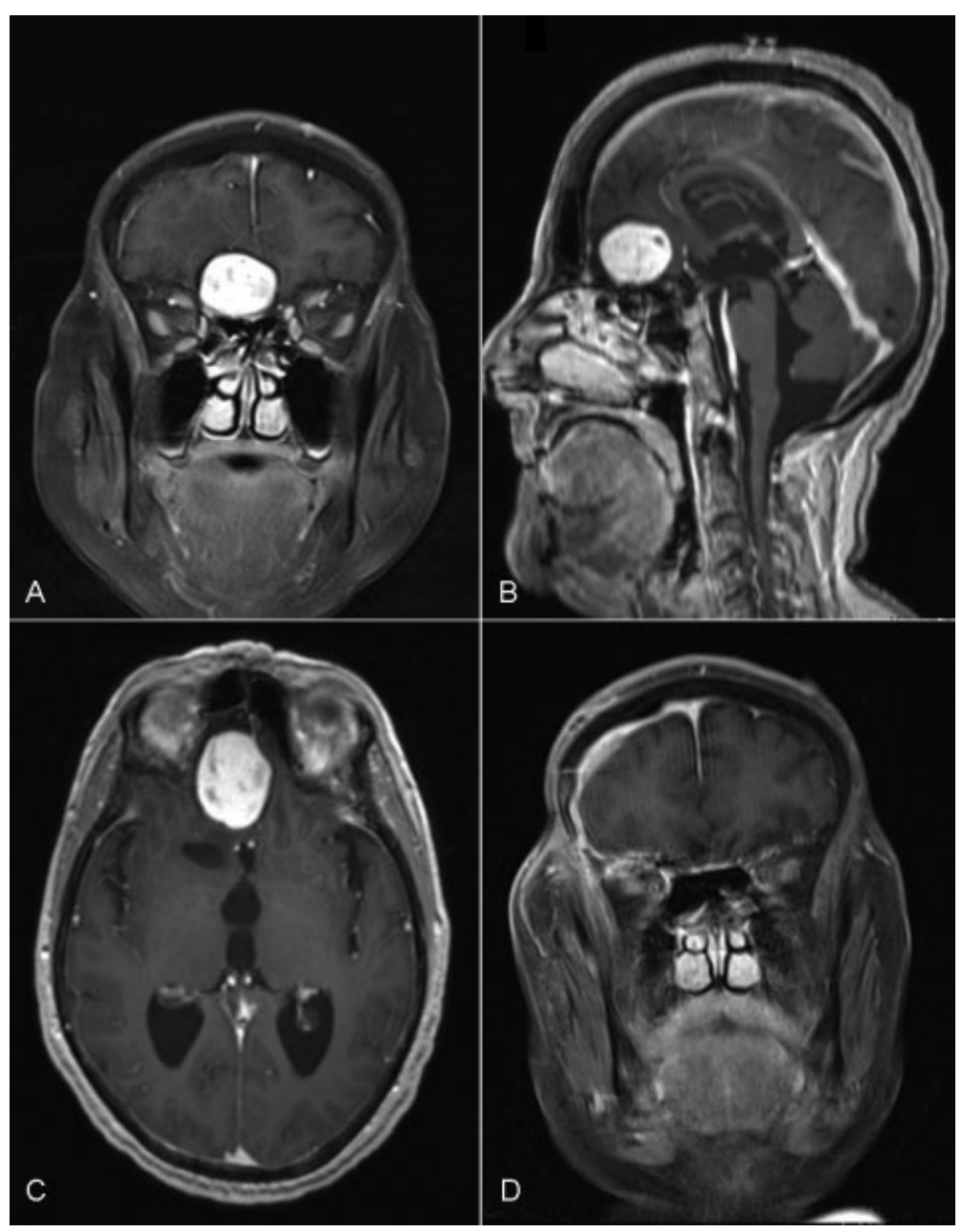

Fig. 1 Coronal (A), sagittal (B), and axial (C) T1-weighted, gadolinium-enhanced, brain MR image demonstrating a well-circumscribed, homogenously enhancing, extra-axial, anterior cranial fossa lesion eroding the ethmoid bone. Coronal (D) T1-weighted, gadolinium-enhanced, brain MR image showing gross total resection of the tumor.

received

March 5, 2017

accepted

May 25, 2017

published online

August 29, 2017

\begin{abstract}
DOI https://doi.org/
10.1055/s-0037-1606308. ISSN 2277-954X.
\end{abstract}

License terms of India

(c) $(1) \$$ 


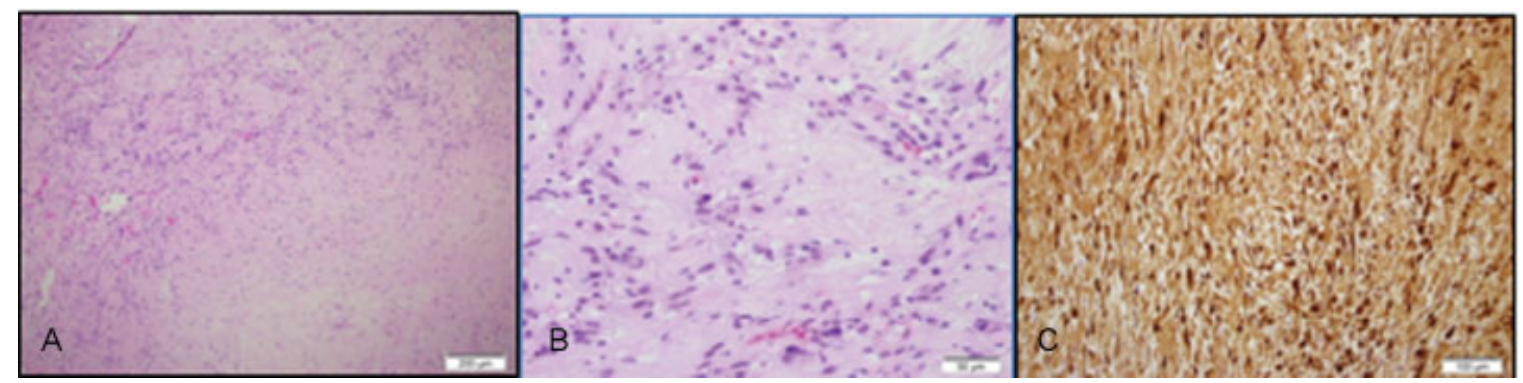

Fig. 2 Histopathologic examination revealed pauci-cellular and more cellular regions (A) composed of spindle cells, without marked nuclear atypia or increased mitotic activity, with ill-formed nuclear palisading (B), diffusely immune-positive for S-100 (C).

(-Fig. 2). At the 1-year follow-up, the patient had right-sided anosmia.

Olfactory groove schwannomas are rare, extra-axial, benign tumors. In contrast to other intracranial schwannomas, they frequently affect young males. ${ }^{1,2}$ Moreover, since the olfactory bulb is devoid of Schwann cells, ${ }^{1,3}$ their pathogenesis is unclear with several theories proposed: The developmental theories suggest mesenchymal pial cell transformation into Schwann cell or aberrant neural crest cell migration.1,2,4 The nondevelopmental theory suggests origin from Schwann cells present in adjacent structures. ${ }^{1,2,4}$ Finally, reactive Schwann cell formation from multipotential mesenchymal cells has also been proposed. ${ }^{1}$

Histopathologic findings pathognomonic for schwannoma include densely packed elongated cells with palisading nuclei (Antoni A pattern) alternating with less cellular regions (Antoni B pattern). ${ }^{3}$ On immunohistochemistry, schwannomas stain was positive for $\mathrm{S}-100^{3}$ and CD-57 (Leu$7)^{2,4}$ and negative for smooth muscle $\alpha$-actin. ${ }^{4}$ Management should be individualized, and includes observation, surgical resection, and radiosurgery. ${ }^{3}$
In conclusion, the pathogenesis of olfactory groove schwannomas remains unclear. They should be included in the differential diagnosis of anterior cranial fossa neoplasms.

\author{
Funding \\ None. \\ Conflict of Interest \\ None.
}

\section{References}

1 Choi YS, Sung KS, Song YJ, Kim HD. Olfactory schwannoma-case report. J Korean Neurosurg Soc 2009;45(02):103-106

2 Mirone G, Natale M, Scuotto A, Rotondo M. Solitary olfactory groove schwannoma. J Clin Neurosci 2009;16(03):454-456

3 Carron JD, Singh RVP, Karakla DW, Silverberg M. Solitary schwannoma of the olfactory groove: case report and review of the literature. Skull Base 2002;12(03):163-166

4 Gangadharan J, Mahadevan A, Ramalingaiah AH, Ramesh A, Devi BI. Clinical, radiological, surgical, and pathological determinants of olfactory groove schwannoma. Indian J Neurosurg 2014;3(02):86 